\title{
Una aproximación a la sociología de los cuerpos y las emociones en los discursos históricos fundacionales de Villa Nueva y Villa María (Córdoba-Argentina)
}

\section{An approach to the sociology of bodies and emotions in the founding historical discourses of Villa Nueva and Villa María (Córdoba-Argentina)}

\author{
Guillermo Bovo ${ }^{1}$ \\ Emanuel Barrera Calderón²
}

\begin{abstract}
Resumo: As cidades de Villa Nueva e Villa María estão localizadas em cada banco do rio Ctalamochita, no sudeste da província de Córdoba (Argentina). Esta área era um enclave na era colonial e hoje tornou-se uma confluência de diferentes ferrovias e rotas nacionais e provinciais. Os discursos históricos baseados nos momentos fundamentais dessas cidades foram constituídos recorrendo a diversos antagonismos, como Progreso-Tradición, LiberalismoConservadorismo, secular-clerical, entre outros, representados nas memórias dos historiadores. Especificamente, a idéia de Villa María está subjacente a uma cidade próspera e planejada a partir de suas fundações e a Villa Nueva como detida no tempo, com características conservadoras e clericais. Nesta proposta que trazemos, entendemos que a emotividade é uma maneira de entender fenômenos sociais. Eles não são apenas entendidos através do conhecimento, mas também através das emoções. Nesse sentido, os discursos históricos também são compostos de sensibilidades, isto é, de percepções, sensações e emoções e não apenas de registros e dados. O objetivo deste trabalho é analisar a construção de discursos históricos sobre o passado fundacional de Villa Nueva e Villa María através da sociologia de corpos e emoções. Isso será através da análise do discurso de um corpus de estudo integrado pela historiografia em questão.
\end{abstract}

Palavras-chave: Discursos históricos, sociología de los cuerpos y las emociones, mecanismo de soportabilidad social.

Resumen: Las ciudades de Villa Nueva y Villa María están situadas en cada orilla del río Ctalamochita al sudeste de la provincia de Córdoba (Argentina). Esta zona fue un enclave en la época colonial y en la actualidad se ha convertido en confluencia de diferentes vías férreas y de rutas nacionales y provinciales. Los discursos históricos basados en los momentos fundacionales de estas ciudades, se constituyeron recurriendo a diversos antagonismos, como Progreso-Tradición, Liberalismo-Conservadurismo, laico-clerical, entre otros, representados en las memorias de los historiadores. Concretamente, subyace la

\footnotetext{
${ }^{1}$ Licenciado en Ciencias de la Comunicación (Universidad Nacional Villa María) Investigador de la UNVM y Becario doctoral del Consejo de Investigaciones en Ciencia y Tecnología (Conicet). guillermobovo@gmail.com

${ }^{2}$ Licenciado en Ciencia Política (Universidad Nacional Villa María) Docente e investigador de la UNVM y Becario doctoral del Consejo de Investigaciones en Ciencia y Tecnología (Conicet). ebarreracalderon@gmail.com
} 
idea de Villa María como una ciudad pujante y planificada desde sus bases y Villa Nueva como detenida en el tiempo, con rasgos conservadores y clericales. En dicha propuesta que traemos, entendemos que la emocionalidad es una forma de comprender los fenómenos sociales. No sólo se los comprende a través del conocimiento sino también de las emociones. En este sentido, los discursos históricos están compuestos también de sensibilidades, es decir, de percepciones, sensaciones y emociones y no sólo de registros y datos. El objetivo de este trabajo es analizar la construcción de discursos históricos sobre el pasado fundacional de Villa Nueva y Villa María a través de la sociología de los cuerpos y las emociones. Esto será a través del análisis de discurso de un corpus de estudio integrado por la historiografía en cuestión.

Keywords: Discursos históricos, sociologia de corpos e emoções, mecanismo de resistência social.

\section{Introdução}

As cidades de Villa Nueva e Villa María estão localizadas em cada banco do rio Ctalamochita, no sudeste da província de Córdoba. Esta área, localizada em um ponto intermediário entre as cidades de Rosario e Córdoba, tem sido um enclave onde a rota do Caminho Real passou e que mais tarde seria a confluência de diferentes ferrovias e rotas nacionais e provinciais. Esta situação de cidades adjacentes separadas por uma delimitação geográfica física ou administrativa passa por vários exemplos em todo o país (e até mesmo no mundo). Podemos encontrar exemplos paradigmáticos, como a cidade de São Francisco (província de Córdoba) e a fronteira (província de Santa Fé), onde uma rua separa ambas as cidades, mas também as duas províncias. Essas cidades contêm histórias que dialogam e que fazem parte de identificações específicas de cada uma. As origens de Villa Nueva e sua constituição jurídico-política são marcadas em 1826 principalmente pela família Carranza, que fez a doação de terra para criar uma cidade que seria suficientemente importante para as autoridades de Alzada e a comandancia para se mudar para lá. , o que eles conseguiram durante o governo de Manuel López "como uma guarda permanente contra os confrontos com os povos indígenas do norte e do sul". De acordo com o raciocínio feito pelo escultor villanovense Armando Fabre, "Villa Nueva tem esse nome, para diferenciá-lo ou separá-lo do agrupamento de fazendas que estavam na margem do rio, constituindo o assentamento de 'Paso de Ferreira"' (GRANADO, 2011, p.37), isto é, Villa Nueva existe para se diferenciar de uma "Vila Velha". Embora tenha também outros nomes como "Villa Nueva del Paso de Ferreira" e "Villa Nueva del 
Rosario"; para se tornar Villa Nueva, por volta de 1836 (GRANADO, 2011).

Por outro lado, Villa María não teve um ato fundamental como outras populações geralmente tiveram. Manuel Anselmo Ocampo, então proprietário das terras do lugar, ordenou que um mapa fosse desenhado com o lote onde a nova população fosse projetada, em frente a Villa Nueva que estava localizada do outro lado do rio. Ocampo era um personagem ligada ao poder político e econômico do tempo que residia em Buenos Aires, ele havia comprado a terra de seu tio Mariano Lozano, que por sua vez recebeu de proprietários anteriores (RÜEDI, 2016). A população era principalmente imigrantes europeus que se juntaram aos que moravam na região e os africanos que vieram do mercado de escravos que tinham um desenvolvimento importante na província. Durante anos, nenhuma data foi comemorado como um aniversário da cidade, levaria algumas décadas para que uma comissão concordasse na data da fundação em 27 de setembro de 1867.

Como Rüedi (2016) menciona, no início do século XIX, a figura da villa foi imposta para nomear as localidades como uma alternativa hierárquica, uma vez que era maior que a aldeia e menor do que a cidade. Conta a anedota que Ocampo coloca Maria na cidade que se origina, em referência a sua filha mais velha. Desta forma, cada vila emerge indicando uma existência anterior, como Villa Nueva (de acordo com o 'rancherío') ou Villa María (da filha mais velha de Ocampo). Mesmo essa existência anterior, que é significativa para a constituição identitária, é baseada na comparação antagônica sobre a possibilidade de pensar como uma totalidade territorial.

Esses antagonismos descansam, fundamentalmente, na emotividade dos historiadores, uma vez que não só os discursos históricos são reconstruídos através do conhecimento, mas também das emoções. Nesse sentido, esses discursos também são compostos de sensibilidades, isto é, de percepções, sensações e emoções e não apenas de registros e dados. Nesse sentido, o objetivo deste trabalho é analisar a construção de discursos históricos sobre o passado fundacional de Villa Nueva e Villa María através da sociologia de corpos e emoções.

Para este propósito, a estratégia argumentativa que selecionamos é a seguinte: a primeira parte será constituída por dois momentos teórico-conceituais, um referente à 
abordagem da sociologia dos corpos e emoções e o outro, sobre os discursos históricos. A segunda parte será focada na análise dos discursos históricos fundamentais das Villas nas historiografias locais. Finalmente, vamos ensaiar algumas reflexões abertas que tentarão explicar uma análise discursiva da historiografia.

\section{As principais discussões sobre a sociologia dos corpos e emoções. Fantasmas e fantasias e mecanismos de resistência social}

A sociologia dos corpos e emoções apresenta uma jornada histórica, com diferentes nuances teóricas e epistemológicas, que abre e complica esse campo de estudo. Nesse sentido, aqui pretendemos enunciar alguns dos possíveis deslocamentos conceituais. Começamos a compreender a experiência em relação a um assunto que não é apenas afetado por um evento, mas passou por ele. Para Dominick Lacapra (2006), este processo de "[...]" ter passado por algo "alude tanto à pessoa que teve a experiência quanto àqueles que se identificam com ela, ou com aqueles que simpatizam com ela e simultaneamente reconhecem e eles respeitam a alteridade e até rejeitam a identificação" . Para este historiador: "[...] é essencial levar em consideração o processo de" passar por algo "para qualquer definição aceitável de experiência, um processo que envolveria uma resposta afetiva - e não apenas cognitiva - onde a emotividade seria relacionada à tentar entender o outro "(2006, p.68). Neste contexto, as noções de sociologia de corpos e emoções tiveram um desenvolvimento teórico metodológico no último quarto do século 20, onde, em primeiro lugar, o olhar neurofisiológico (LUNA ZAMORA, 2010) prevaleceu. Como Melucci (SCRIBANO, 2012 apud MELUCCI, 2001, p. 95) salienta, o cérebro é o órgão mais "social" dos corpos e o limite mais "natural" das emoções. Por conseguinte, Scribano (2009) reforça essa ideia, mencionando que os corpos são tais, dada a sua conexão com o meio ambiente / ambiente (condições materiais de existência) através dos processos complexos que se originam na interação entre (com e de) o cérebro , o sistema nervoso central e as energias. Ou seja, no cérebro, os processos de construção social de corpos e emoções mediados por um conjunto de modularidades interativas entre as "causas" químicas e elétricas dos sistemas de vida que articulam são "alojados" (de forma complexa e indeterminada). as capacidades que possuem energia para condicionar a possibilidade (ou não) de produzir / reproduzir e / ou equilibrar / desbalancear 
a existência desses corpos / emoções (SCRIBANO, 2012).

Essa coordenação permitiu uma mudança no eixo dos estudos, transformandoo em uma perspectiva ligada à interação social e à relação agente / estrutura. Kemper (1990), por meio de seu trabalho em equipe com estudantes, tentou recuperar suas perspectivas e perspectivas para investigar emoções. Como vimos, ele afirma que inicialmente o estudo do corpo e das emoções foi reduzido aos problemas da mente humana. Isso indica que o estudo desta relação renasceu no interesse de encontrar novas formas de investigar o conhecimento. Nesse sentido, o autor argumenta que, desde 1960, a sociologia tem focado sua atenção na expressividade do ser.

Por sua vez, Collins (KEMPER, 1990 apud COLLINS, 1981, p.6) argumenta que a perspectiva das emoções pode ser pensada a partir de duas dimensões em termos de estratificação: 1- potência e 2 estados. Quanto ao primeiro, considere as interações estruturadas pela divisão de papéis entre a "ordem dada" e a "ordem dos beneficiários", principalmente na ampla escala organizacional social, que Collins (1981) vê como central para a estratificação de sistemas modernos. Neste ponto, com o objetivo de dominar, a "ordem dada" fornece "energia emocional" para a interação, a fim de satisfazer a dominação. Por outro lado, a "ordem dos beneficiários" freqüentemente experimenta a perda de sua energia emocional, seus interesses e seus desejos que são abandonados e ignorados (KEMPER, 1990 apud COLLINS, 1981, p.6).

Em relação à segunda dimensão, os estados rituais são considerados independentes de poderes baseados em rituais, uma vez que existe uma tensão na rede de interação entre o cosmopolita, o local, entre outros elementos, que constituirão os padrões de interação nesta linha, o autor apresenta uma perspectiva acumulada dos rituais (com crescimento ou diminuição da energia emocional) constituindo a estrutura macro da estratificação. Essas obras, de acordo com Collins (KEMPER, 1990 apud COLLINS, 1981, p.6) são a base para estudos de emoções. É importante notar que, nesta perspectiva estrutural em tensão com o micro, entendendo-o a partir de uma posição de agente, interessado no assunto através de uma série de estudos sobre estados emocionais como raiva, medo, euforia, que por sua vez, de acordo com o autor, eles crescem ou diminuem a energia emocional nos padrões estruturais (KEMPER, 1990 apud COLLINS, 1981, p.6). 
Por sua parte, Clark (KEMPER, 1990), em consonância com uma idéia da gestão das emoções (próprias e outras), quer explicar como as pessoas conhecem, defendem ou estendem seu lugar nas relações sociais. $O$ autor considera que esse lugar é um indicador construído contra outros nas dimensões de poder, status e distância (ou intimidade). Esta posição pela qual um indivíduo pode reivindicar ou assumir como um direito em interação com outros, que, por sua vez, têm seu lugar e direitos (KEMPER, 1990, p.17).

Nesse sentido, o autor afirma que o lugar engloba etiqueta, vocabulário, proximidade do espaço, nível de contato. Clark (KEMPER, 1990, p.17) argumenta que aqueles que ocupam um lugar mais alto operam mais livremente nesses modelos, enquanto aqueles com um lugar mais baixo são mais restritos. De acordo com o autor, embora a interação social estabeleça diretamente um lugar, esses direitos são limitados pelo próprio conceito, onde o poder dita mais ou menos lugar como próprio ou meritório (p.17). Retornando, esta proposta de apresentar algumas contribuições em relação aos estudos sobre corpos e emoções, nos concentramos nas posições da microsociologia que acentuam ainda mais o assunto e suas relações com o grupo social.

Luna Zamora (2010) explica da seguinte maneira:

Na verdade, o surgimento do indivíduo na segunda metade do século
XX, e afeições correlacionada com a fragmentação das "sociedades ho-
mogêneas" coesas por altos valores e significados compartilhados, por
um lado, e o surgimento de perspectivas científicas microssociológica,
Por outro lado, eles geraram novas perspectivas que privilegiaram a cen-
tralidade do indivíduo como estudo de pequenos grupos sociais em sua
interação diária, sendo a subjetividade tornando-se relevante. Este foi
o novo cenário que possibilitou a criação do campo da sociologia das
emoções como uma arena específica de análise (p.15).

Esta centralidade do indivíduo destaca a tensão que poderia ser construída através da interação diária, onde a relação entre estrutura / sujeito social nos permite entrar através das fissuras de uma sensibilidade que é re-elaborada, reestruturada a partir de de uma forma de expressão. A partir dessa caracterização, plural leituras matriculados em uma sociologia dos corpos e emoções da América Latina, convergem para retomar e enfatizar a importância das relações de dominação capitalista, com vista a reconhecer os perfis de projeto imperial que re-mapeia sociedades latino-americanas contemporâneas.

Rogelio Luna Zamora (2010) seguindo Armon-Jones (1986) e Hochschild (1990) sugerem uma classificação de estudos sobre emoções em três grupos sistematizados 
de acordo com a importância atribuída a eles nos aspectos biológicos ou culturais, como base de sua origem: o naturalista orgânico, o construcionismo não-radical e o construcionismo radical.

Sintetiza Scribano (2012, p.94) "Como para as perspectivas na América Latina, mencionar estudos sociais sobre os corpos de Tijoux, Lindon, Grosso, Pedraza, Kogan, entre outros e em relação aos estudos sobre as emoções Koury, Lua Zamora, Camarena, Aguiluz também são as mais destacadas".

A ligação entre o corpo, as emoções e o conflito pode ser esclarecida se considerarmos que os sentimentos surgem das emoções, e as emoções provêm de sensações - que são as percepções anteriores e posteriores (SCRIBANO, 2007).

Nesse sentido, as emoções são uma dimensão para explicar os processos sociais que de outra forma não conseguem explicar de forma completa por que as práticas dos assuntos. Diante disso, de uma sociologia de corpos e emoções, podemos seguir o caminho para encontrar pistas que nos levem a:

- Compreender o significado que os atores dão às suas práticas.

- Identificar nós conflitantes que emergem na compreensão diária.

- Dê conta de como a sociedade que se torna um corpo pode ser rastreada a partir da análise de certas emoções sociais.

É o lugar e topos do conflito através do qual passam (boa parte) a lógica dos antagonismos contemporâneos. A partir daí, é possível observar a constituição de uma economia política de moralidade (SCRIBANO, 2012), isto é, modos de sensibilidades, práticas e representações que materializam a dominação. Uma sociologia de corpos e emoções envolve a aceitação de que, se alguém quiser conhecer os padrões de dominação de uma determinada sociedade, é necessário analisar: quais são as distâncias que a mesma sociedade impõe sobre seus próprios corpos, de que forma os marca? , e como a disponibilidade de sua energia social está configurada. Assim, a política dos corpos, ou seja, as estratégias que uma sociedade aceita para responder à disponibilidade social dos indivíduos, é um capítulo, e não menos importante, da estruturação do poder. Essas estratégias são aninhadas e "fortalecidas" pela política de emoções que tendem a regular a construção da sensibilidade social. 
A partir deste ponto, Scribano (2013) ocupa o Vygotsky, argumentando que, quando os sujeitos se expressam, quando constroem uma imagem, sintetizam de uma maneira ou de outra três processos concomitantes: a história social das possíveis imaginações produziu o corpo, a conexão do sujeito com a realidade em que sua ação está inscrito e o conjunto de emoções que ele carrega e cria associado a suas próprias crenças ou pensamentos (SCRIBANO, 2013, p.76). Por outro lado, Magallanes et al (2014) começam a partir de três pressupostos, por isso propõem uma distinção que é fundamental para pensar sobre o olhar, que se poderia dizer, epistemológico de uma sociologia de corpos e emoções. Desta forma, o primeiro aspecto, de caráter ontológico, afirma que os corpos e as emoções são inseparáveis e são inerentemente co-implicados. As emoções estão passando por todas as práticas sociais que os sujeitos executam, como corpono-mundo. O segundo, de natureza teórica, considera que a sociedade é configurada a partir da desigualdade e que, entre as estruturas e os sujeitos, é estabelecida uma relação de interpenetração recíproca pela qual os sujeitos formam as estruturas e vice-versa. A este respeito, a corporeidade tem um lugar especial como locus de ordem e conflito. O terceiro, de natureza metodológica, supõe que é possível capturar, de emoções e percepções, certos estados de sensibilidade que estão conectados e / ou desconectados da estruturação social. (MAGALLANES et al, 2014, p83). Para entender isso, Scribano (2009) argumenta que "percepções, sensações e emoções constituem um tripé que nos permite entender onde as sensibilidades se baseiam" (p.145). Os agentes sociais conhecem o mundo através de seus corpos. Desta forma, um conjunto de impressões afeta as formas de "troca" com o contexto sócio-ambiental. Essas impressões de objetos, fenômenos, processos e outros agentes estruturam as percepções que os indivíduos acumulam e se reproduzem. Uma percepção dessa perspectiva constitui uma maneira naturalizada de organizar o conjunto de impressões que são dadas em um agente. Essa rede de impressões molda as sensações que os agentes "fazem" o que pode ser designado como mundo interno, externo, social, subjetivo e "natural". Esta configuração consiste em uma tensão dialética entre a impressão, a percepção e o resultado, o que dá o "sentido" do excedente às sensações. Ou seja, localiza-os mais aqui e além da dialética acima mencionada. As sensações como resultado e como antecedente das percepções dão origem às emoções como efeito do processo de adjudicação e correspondência entre 
percepções e sensações. Por outro lado, as emoções entendidas como conseqüências das sensações podem ser vistas como o quebra-cabeça que vem como ação e efeito de sentimento ou sentimento (SCRIBANO, 2012). As emoções estão enraizadas nos estados de sentir o mundo que permitem a percepção de sustentação associada a formas de sensações socialmente construídas. Ao mesmo tempo, os sentidos orgânicos e sociais também nos permitem transmitir o que parece único e irrepetível, como as sensações individuais, e elaborar o "trabalho despercebido" da incorporação da emoção social. Nesse sentido, Scribano (2012) argumenta que identificar, classificar e tornar a relação entre sensações, percepção e emoções críticas nos permitirá compreender os dispositivos para regular as sensações que o capital tem para a dominação social.

A sociologia dos corpos / emoções envolve a aceitação de que se você quiser conhecer os padrões de dominação em uma determinada sociedade, você deve analisar (SCRIBANO, 2012): quais são as distâncias que a mesma sociedade impõe sobre seus próprios corpos, de de que maneira você marca e como suas energias sociais estão disponíveis. Na mesma direção, é possível afirmar que os sistemas de dominação existentes, entre as distâncias estabelecidas, dão origem a: a) os padrões de inércia dos corpos, b) o seu deslocamento potencial, c) os modos sociais de sua avaliação, d ) e os tipos de uso social aceitos. A dominação não aparece no corpo em todo o espaço do tempo da mesma maneira; as marcas corpóreas são inscrições socialmente estabelecidas pelo processo de dominação em que uma determinada sociedade está afundada. Ou seja, a geometria do corpo é baseada em uma geocultura e uma geopolítica de dominação. Assim, a política dos corpos, ou seja, as estratégias que uma sociedade aceita para responder à disponibilidade social dos indivíduos, é um aspecto, e não menos importante, da estruturação do poder. Essas estratégias são aninhadas e "fortalecidas" pela política de emoções que tendem a regular a construção da sensibilidade social. É neste quadro que fantasmas e fantasias sociais adquirem um papel fundamental.

Nesse contexto, entendemos que os mecanismos de apoio social são estruturados em torno de um conjunto de práticas criadas em um corpo orientado para a prevenção sistemática do conflito social. Os processos de deslocamento das conseqüências dos antagonismos são apresentados como cenários especulares e desbloqueados de um espaço-tempo. Vida social "se-hace" como un-siempre-así (SCRIBANO, 2012). Os dis- 
positivos para regular as sensações consistem em processos de seleção, classificação e elaboração de percepções socialmente determinadas e distribuídas. O regulamento envolve a tensão entre os sentidos, a percepção e os sentimentos que organizam os modos especiais de "apreciar-no-mundo" que as classes e os assuntos possuem.

As cadeias e os esquemas cognitivo-afetivos que conectam (e desconectam) as práticas sociais como narrações e visões do mundo constituem o corpo, constituem os processos caracterizados aqui como ideológicos. Os mecanismos e dispositivos indicados são uma dobradiça prática e processual onde as interseções entre emoções, corpos e narrativas são instanciadas (SCRIBANO, 2009).

Como já foi dito, entre eles há dois elementos que, do ponto de vista sociológico, adquire relevância: fantasias e fantasmas sociais. Alguns são o inverso dos outros, ambos referem-se à negação sistemática de conflitos sociais. Enquanto as fantasias ocluem o conflito, eles invertem (e consagram) o lugar do particular como um universal e tornam impossível a inclusão do sujeito nos motivos fantasiados, os fantasmas repetem a perda conflituosa, lembre-se do peso da derrota, desvalorizem a possibilidade de contraação em face de perda e falha. Um dos truques mais importantes desses dispositivos não tem um caráter propositalmente estruturado: eles não são escritos ou ditos, são práticas que bloqueiam e desbloqueam a potencialidade do conflito, seja como "sem razão", ou como uma ameaça. Fantasias e Fantasmas nunca fecham, são contingentes, mas sempre operam, tornam-se práticos (SCRIBANO, 2009).

\section{Os discursos históricos como práticas, processos de produção e o lugar dos agentes sociais}

Vimos como as emoções são um dos aspectos mais centrais e omnipresentes da experiência humana. Eles nos alertam sobre as coisas que importam e por que elas importam. No entanto, para visualizar o potencial das emoções como indicadores metodológicos do grau de internalização e compromisso gerados por proposições culturais em uma pessoa ou grupo social, é necessário não considerá-las como manifestações de irracionalidade ou meros estados subjetivos. Em vez disso, é necessário, como é comum nas teorias cognitivas das emoções e na sociologia das emoções, compreendê-las como portadoras de interpretações e significados dependentes de considerações soci- 
ais e culturais (por exemplo, de natureza ética e normativa) que definem a momentos e as circunstâncias em que cada um deles deve ser experimentado e com qual grau de intensidade deve ser feito. Também é necessário assumir que eles são criados e sustentados a partir de interações intersubjetivas e relações sociais. O histórico como dimensão permite investigar a sensibilidade da experiência narrada pelos historiadores sobre o passado fundador, que apresenta uma historicidade complexo, de acordo com esses relatos historiográficos, onde o conflito é constituído como uma característica de identificação dos habitantes de Villa Nueva em relacionamento com outro, habitante de Villa María.

Reforçando essa tensão, Barrera Calderón e Bovo (2017) consideram:

[...] que a mesma historiografia que fez um esforço incansável para atribuir elementos distintivos nas identificações culturais dos fenômenos villanovense e villamariense gentilicios. Esforço que não produz efeitos no momento da narração dos processos, onde as histórias se cruzam, dialogam e questionam (p.21).

A contribuição de Zamora Moon (2010) é um pontapé para investigar as sensibilidades que emergem nas construções discursivas de historiadores de Villa Nueva e Villa Maria, especificamente em casos de Granado Pablo e Ruben Rüedi, respectivamente. Dirigir o discurso como uma prática e, portanto, como um processo, nos permite abrir a análise à questão das condições sociais onde o processo de produção está inserido e, inevitavelmente, nos remete para o agente social que produz esse discurso. Por sua parte, a conceituação do agente social como uma capacidade de geração baseada no controle de recursos, nos permitirá analisar duas dimensões no discurso; primeiro, as características de acordo com a posição relativa do autor e segundo, o que constitui a sua capacidade de impor. Como Costa e Mozejko (2001) dizem, o tratamento das condições sociais de uma prática discursiva pode ser analisado a partir da noção de lugar. Ou seja, o assunto que o produz ocupa, em função dos recursos e propriedades socialmente valorizadas que ele controla, uma posição relativa em um enredo específico de relações. Esta posição implica uma competência diferenciada para a sua intervenção que estabelece um espaço possível para suas operações discursivas.

Vemos como o lugar constitui um princípio explicativo das práticas, não para reduzi-las ao funcionamento de um mecanismo estrutural que transcendesse o assunto, 
mas para torná-los inteligíveis, em relação às possibilidades e limites que estabelecem as condições sociais de seu desempenho (COSTA e MOZEJKO, 2001).

No caso deste trabalho, analisar a produção de discursos em que se propõe uma visão do passado fundacional, em relação à posição é certamente necessária, mas deve ser complementada com ênfase no caráter relacional da posição (COSTA e MOZEJKO, 2001). Desta forma, os historiadores em sua capacidade de "agência" como legitimadores de um critério de autoridade disputam o "sentido correto da história", isto é, o predomínio de uma visão sobre os outros.

Com a contribuição de Costa e Mozejko (2001), a dimensão relacional e controversa está subjacente a todo discurso, uma vez que o enunciador é construído com base nas oposições e equivalências estabelecidas com outros enunciadores, configurando assim o próprio lugar. Por sua vez, o agente social realiza o trabalho de produzir o discurso de um lugar que, como um lugar social, é fundamentalmente uma capacidade diferenciada de relacionamento dentro de um sistema que sempre coloca em risco as relações de poder.

Nesse sentido, as estratégias utilizadas no nível do discurso e através das quais o enunciador é construído são o resultado das opções que o autor, como agente social, faz durante o processo de produção dentro das margens do movimento que o seu próprio $A$ capacidade de relacionamento permite-lhe:

\begin{abstract}
O enunciador cujo perfil é delineado das opções que são objetivadas na declaração e que mostram o modo de posicionar-se em relação a outros enunciadores, às normas que consertam as formas de dizer e o que pode ser dito, etc. , torna-se compreensível e explicável como resultado do trabalho que a pessoa que produz o texto desempenha um determinado lugar, de uma certa capacidade de relacionamento e para produzir efeitos lucrativos para sua própria posição relativa permanentemente em jogo (Costa e Mozejko , 2001, p.25)
\end{abstract}

É assim que o texto, produto da prática discursiva, é o resultado de múltiplas decisões não necessariamente conscientes no processo de produção, "Quem fala? O texto aponta para o autor. Ou seja, o texto inclui a exterioridade, então a questão é, onde é falado? Como efeito sensorial de explicar suas práticas" (COSTA e MOZEJKO, 2001, p.12) Para entender o agente social, é fundamental compreender a competência para a ação, como uma probabilidade de fazer dentro de um sistema de relacionamentos. 
Como disse, o local define a especificidade e alcance de sua competência. Este processo contém duas dimensões constitutivas; por um lado, o poder de fazer (capacidade de relacionamento diferenciada) e, por outro lado, a orientação dessa capacidade. Em relação à capacidade diferenciada do relacionamento, isso se refere ao controle diferenciado de recursos, que condiciona quem tem o poder de dizer como é a história. Por essa razão, pensar sobre o lugar, é pensar sobre as posições relativas que decorrem do controle diferenciado dos recursos.

Pensar sobre a relação entre os lugares construídos é pensar no poder como relacionamento e probabilidade. Ou seja, o controle diferenciado dos recursos confere legitimidade ao enunciador, permitindo, no caso dos discursos históricos, ser identificado como um assunto competente para a realização específica. Questionar esta capacidade de historicizar os agentes sociais (com pretensão hegemônica) é o objetivo desse trabaIho. Neste contexto, a historiografia oficial tem um lugar central na produção, invenção e articulação de memórias sociais que são instituídas como dominantes discursivos em determinado momento e em um determinado território. A noção de hegemonia como poder simbólico opera dentro da diferenciação política e faz da cultura, em vez da produção de significados, a forma como as classes dominantes e subordinadas estão relacionadas (GRAMSCI, 2015). Neste caso, a dominação é baseada na disputa sobre recursos e na apropriação desigual de bens materiais ou simbólicos. Desta forma, a noção de hegemonia gramsciana articula as idéias da sociedade política e da sociedade civil que dominam um determinado momento histórico. Desta forma, e estabelecendo uma conexão entre espaço e memória, nós mantemos que os discursos históricos adquirem densidade analítica em relação a disputas simbólicas materializadas em rituais, símbolos, ideologias e formas de tornar o Estado um espaço privilegiado de objetivação. Assim, a suposta "identidade local ou regional" é sempre o resultado de lutas simbólicas e narrativas culturais. Pode-se dizer que a discursividade social (VERÓN, 1986) que articula memórias diversas sempre integra uma significativa (leia uma identidade local ou regional) que não existe na realidade e que, portanto, é sempre contingente. Nesse sentido, não existe uma memória coletiva que não seja elaborada em um quadro espacial e na construção de sujeitos individuais. Da mesma forma, nos permite entender como a sociedade funciona a partir de construções essencializadas e estas podem ser analisadas através de 
imagens, narrativas, simbologias que demonstram que uma identidade coletiva é sempre o resultado de disputas e conflitos sociais. Portanto, observar as memórias que emergem dos discursos históricos fundamentais permite identificar o limiar em que esses discursos dominantes são articulados em um único momento histórico e foram institucionados hegemonicamente.

\section{Fantasmas e fantasias e os mecanismos de viabilidade social em torno de três discursos históricos fundadores de Villa Nueva e Villa María}

Agora vamos investigar os discursos históricos em torno de três eixos que nós enunciamos de acordo com uma série de eventos narrados pelos historiadores locais, que os denominaremos da seguinte maneira: o primeiro sobre catástrofes naturais (como). O ciclone e as epidemias; O segundo que chamamos as pontes estendidas e a terceira é a capitalização das Villas. A partir desses discursos históricos, tentamos algumas tensões com a proposta conceitual de sociologia dos corpos e emoções que Scribano (2009) sustenta através das chaves "fantasias e fantasias" e "mecanismos de viabilidade social", como lugares para observar o funcionamento do dispositivo para regular sensações em discursos históricos. Fantasmas e fantasmas sociais. Alguns são o inverso dos outros, e ambos se referem à negação sistemática de conflitos sociais. Enquanto as fantasias obstruem o conflito, eles investem (e consagram) o lugar do particular como um universal e tornam impossível a inclusão do sujeito nos motivos fantasiados; os fantasmas repetem a perda conflitual, lembrem-se do peso da derrota, desvalorizam a possibilidade de contra-ação antes da perda e da falha. Um dos truques mais importantes desses dispositivos não tem um caráter estruturado antes do tempo: eles não são escritos ou ditos, são práticas que bloqueiam e desbloqueam a potencialidade do conflito, seja como "sem razão" ou como ameaça. Fantasias e Fantasmas nunca fecham, são contingentes, mas sempre operam, tornam-se práticas. (SCRIBANO, 2008, p.90)

\section{Sobre catástrofes (como) naturais. Ciclone e epidemias}

As catástrofes e epidemias que ocorreram em Villa María e Villa Nueva no final do século XIX e início do século XX emergem na literatura histórica trabalhada como características dos discursos sociais como próprias da natureza, fatores condicionantes 
da dinâmica comercial e sem conexão com a intervenção humana . Granado (2011, p.136) enfatiza: "Das inundações, aos ciclones, atravessando toda a gama de epidemias, Villa Nueva teve que suportar como a fênix, subir de suas próprias cinzas e se levantar em um único esforço" .

Por outro lado, a cólera foi uma das primeiras epidemias que puniu esta região, ocorreu em outubro de 1867 (Granado, 2011, Pedernera, 1970) quando o país estava em guerra com o Paraguai, então em Villa Nueva os diferentes contingentes e regimentos destinados a essas frentes de combate estavam estacionados; diferentes grupos também se reuniram para reforçar os guardas. No dia 28 , o cólera havia assumido a cidade, a situação era delicada, de modo que o Superior Governo da Província, o juiz de Alzada Antonio Centeno, comunica o mesmo dia ao Protomédico da Província Luis Warcalde, de modo que Mude imediatamente para Villa Nueva (Granado, 2011).

A este respeito, Granado (2011) ilustra a situação que é experiente naquele momento, apelando para características de um discurso que, de alguma forma, desafia o habitante de Villa Nueva.

O avanço da cólera fez com que as pessoas fugissem de suas casas, é o momento em que muitos valores humanos são esquecidos e permanece apenas para salvar cada um como ele pode. As autoridades também fogem, tanto o município quanto os tribunais de repente se acham acéfalos (Granado, 2011, p.140).

O avanço da epidemia era iminente e agravou-se ainda mais porque não havia medicamentos suficientes ou pessoal qualificado. Com isso, o médico Warcalde toma as medidas preventivas que as circunstâncias aconselham. Enquanto isso, os trens não chegaram à estação de Rosario, parando em Fraile Muerto, porque acreditava-se que este era o portador dos germes da doença, que apareceu em Rosario no dia 15, apenas três dias antes da primeiro caso em Villa Nueva (Granado, 2011; Calvo, 1989).

Outro dos momentos difíceis aconteceu com a inundação que sofreram Villa Nueva, Villa Maria e a região em 1891. Antes disso, da estação ferroviária de Villa Maria é comunicada urgentemente ao governador. Enquanto isso, Granado (2011, p.141) relata a situação de Villa Nueva: 
a cidade com violência incomum. Por outro lado, flanqueava a borda alta pela extremidade sul, derramando-se na zona de chacras e correndo impetuosa pelo barranco dos Castañotes (2011, p.150).

O desastre se espalhou de Villa María para a cidade de Ballesteros, 72 pólos, telégrafo nacional, tinha sido banido pela força da correntada. Não só os problemas naturais e climáticos foram desencadeados, mas também esses eventos tiveram suas conseqüências no arco administrativo e político local. Mesmo, de acordo com o discurso construído pela historiografia oficial, essa inundação causou o revés da Villa Nueva, já que emergia como uma cidade próspera e progressista. Nesta linha, Granado (2011) argumenta: Muitos acreditam que o aumento de 1891 determinou a distância de Villa Nueva dos grandes capitais comerciais que naquela época giravam em sua praça; queremos esclarecer que isso não aconteceu de forma alguma de forma massiva. Aqui estavam os Piattini, os Freytes, o Villasuso, o Soto, o Carranza, o Barcia, o Urtubey, etc. que eram os comerciantes mais fortes da época. O que aconteceu, com poucas exceções, foi aquela Villa Nueva, curou todas as lágrimas das enchentes de 1891, com a única força de seus filhos. Os comerciantes tiveram que recorrer aos seus créditos, para reabastecer as perdas de mercadoria, com as quais limitaram, por vários anos, a quantidade de suas voltas. Eles continuaram em Villa Nueva, mas empobrecidos. Villa Nueva foi reduzida para zero; A partir daí, começou de novo (Granado 2011. p.160). Continuando, este autor indica que houve uma série de inundações do rio durante os primeiros trinta anos do século $X X$, embora as águas não passassem as possibilidades de contenção da barragem.

Nessas linhas discursivas, particularmente no Granado (2011), podemos ver a recorrência do historiador aos mecanismos de viabilidade social, pois apresenta Villa Nueva como uma localidade com capacidade e força para se reconstruir, enfrentar as grandes catástrofes. Ou seja, o conflito é apresentado como natural e quase divino e sua resolução é proposta com base em uma capacidade apoiada pelo esforço conjunto dos villanovenses, que também através deste mecanismo de viabilidade constrói uma maneira de evitar conflitos. Nesse sentido, podemos dizer que, onde esse costume opera e que sempre dos fatos, dos quais Scribano (2012) fala, regula a sensibilidade do discurso da história local que é elaborado em uma estrutura social onde a tensão permanente é apresentada. 


\section{As pontes colocadas}

Poderíamos dizer que o rio Ctalamochita é um limite, uma fronteira e, por sua vez, um ponto de conexão, entre as cidades de Villa María e Villa Nueva. Na época, em direção ao meio do século 19, havia diferentes meios de transporte para atravessar o rio, o cavalo prevalecendo (em algumas partes do curso de água), flutuadores flutuantes também foram instrumentados para transportar mercadorias de um lado da costa para o outro, até um sistema de roldanas com uma corda que atravessava o rio.

O empreendimento inaugural na construção de uma ponte foi responsável pelo vizinho Antonio Santolini, que propôs em 1869 ao município departamental para construir uma ponte de madeira. Esta iniciativa foi aprovada pelo Conselho Deliberativo da Corporação Municipal de Terceiro Down, onde exigiram através de uma cláusula que devia responder com todos os seus ativos como garantia das cargas que seriam transportadas. Do mesmo modo, foi acordada uma taxa para o cruzamento de pedestres ou equídeos (CALVO, 1989; PEDERNERA, 1970; RÜEDI, 2016). De acordo com RÜEDI (2016), a ponte teve uma vida curta porque um dia o rio Ctalamochita cresceu devido a fortes chuvas e a ponte foi derrotada em suas bases, que a destruíram. A ponte também afundou os sonhos empresariais e o investimento do ambicioso Antonio Santolini, mas, na memória coletiva, a ponte desembaraçada de madeira foi gravada como precursora dos outros que ao longo dos anos se aproximaria como armas de fraternidade entre os Duas casas ribeirinhas (Rüedi, 2016: 43). Após esta ponte que durou pouco tempo, os moradores de Villa Nueva solicitaram ao governo nacional, especificamente o ministro Dalmacio Vélez Sarsfield, a construção de uma ponte que uma Villa Nueva com a estação ferroviária Villa María (GRANADO, 2011; CALVO, 1989). ). No discurso recriado pelos historiadores locais, o gerenciamento da ponte gerou posições conflitantes entre Villa María e Villa Nueva. Embora fosse possível ao presidente Sarmiento comprar duas pontes para a Itália, onde uma delas estava destinada à atual cidade de Bell Ville e a outra para Villa Nueva-Villa María, esta massa de ferro não poderia ser colocada porque era curta, o que teve que ser reestruturado para ser inaugurado em $1^{\circ}$ de janeiro de 1881 (RÜEDI, 2016; PEDERNERA, 1970). Enquanto isso, as disputas políticas foram afiadas, onde "as manobras políticas do povo da Villa María, impediram qualquer trabalho em favor da ponte, para favorecer a chegada de mercadoria através de outras estradas para 
a estação ferroviária" (GRANADO, 2011: 198).

Esta ponte, chamada Vélez Sarsfield, durou até 1927, sua estrutura colapsou em uma de suas partes centrais ao lado de Villa María. No entanto, outro foi inaugurado em 1930 e foi nomeado Juan Bautista Alberdi, que foi construído no local onde a ponte trazida da Itália foi originalmente colocada (RÜEDI, 2016).

A colocação das várias pontes tem um particular acento principalmente como um lugar para resolver antigos litígios, como afirmou Granado (2011). Ao mesmo tempo, Rüedi constrói uma história "amigável" entre as duas aldeias, onde o conflito tem um caráter anedótico: "o tempo era responsável pela geminação das duas cidades e pela construção de pontes sociais, culturais e emocionais ..." (2016 p.105) .

Com a proposta de visualizar os antagonismos, ocorreu um evento no último domingo de Carnaval em 1904, quando duas bandas de gladiadores (uma de Villa María e outra de Villa María): lutaram no rio por várias rodadas e com a presença de um árbitro de combate que terminou a luta antecipadamente dado o dano físico, concedendo a vitória a Villa Maria antes da queixa de Villa Nueva. Esta história de um corte ao lado da literatura ilustra as situações de disputa vividas, no início do século 20 , entre as duas localidades (RÜEDI, 2016, p.128)

Neste fragmento do discurso histórico fundacional de ambas as cidades, podemos ver como a noção de fantasias e fantasias opera nas sensibilidades enunciadas pelos historiadores: podemos dizer que o fantasma da Villa Nueva é Villa María, que é apresentada como uma localidade progressista, secular e comercial, o que oculta o primeiro, enquanto a fantasia para Villa María, como o mundo do desejado é o que Rüedi (2016) sustenta, de "... a irmandade ...", "... de construir pontes sociais, culturais e emocionais..."

Essas pontes simbólicas que parecem enfrentar mais do que unir as duas cidades, encontraram em 1871 uma abordagem súbita. Onde o Congresso argentino aprovou um projeto de lei que federalizou um território, estabelecendo Villa María como a Capital Federal do país. O que durou muito pouco, já que, quando a Lei chegou ao Poder Executivo, o presidente da Nação Domingo Faustino Sarmiento vetou-o, para o qual nunca esteve em vigor, embora permaneça na memória que esta cidade Era a capital do país. 
A capitalização da (s) aldeia (s) é um tema presente na historiografia local. Por sua vez, no projeto de lei, embora não seja feita muita referência, de acordo com a lei proibida, a capital do país foi designada em uma área não superior a 225 quilômetros quadrados, de cada lado do rio Ctalamochita, O que a capital do país não pode ser concedida nem a Villa María nem a Villa Nueva (GRANADO, 2011). Neste sentido, Granado (2011) diz em referência a isto:

[...] este tipo de festividade só corresponde à mentalidade das pessoas que ainda são imaturas ou que não têm nenhum fato histórico de valor real para lembrar e celebrar [...] exortamos as pessoas de Villa Nueva a esquecer o fato sem qualquer transcendência. , se nossa cidade não foi declarada capital federal, apenas um de seus fatos históricos vale mais, muito mais do que uma Lei que foi vetada em tempo hábil (p.264).

Por outro lado, Rüedi (2016) conta a capitalização enfatizando a posição da mídia gráfica da época (El Nacional, jornal dirigido por Dalmacio Vélez Sarsfield e La Nación, liderado por Bartolomé Mitre). O Nacional expressou: "por sua magnífica posição na margem esquerda do Terceiro Rio, cercada por imensas florestas e terras férteis, atraiu a atenção de todos" (RÜEDI, 2016: 42). Enquanto La Nación enunciou:

Na Villa María não haverá distrações. Um homem não pode ir ao teatro ou ter uma boa hora de sociedade depois de dar doze horas para trabalhar. Se levarmos o deserto ao governo nacional, os índios virão e levá-lo-ão, os montoneros virão e eles poderão fazê-lo em cada passo (RÜEDI, 2016, p.42).

A partir disso, pode-se dizer que a possibilidade truncada de capitalização das moradias reverberou ainda mais nas sensibilidades dos aldeões de Villa María que, por um momento, deixaram seus antagonismos pertencerem a uma espécie de totalidade de identidade.

\section{Considerações finais}

Vimos que as emoções são as formas pelas quais experimentamos o mundo e as respostas emocionais refletem a cultura sempre que elas são moldadas por ela. Os sujeitos significam imagens e práticas culturais, animam e recriam-nas através de processos - projeção, introjeção - relacionados à sua própria história, com estratégias e práticas intrapsíquicas e interpessoais no quadro cultural. O sentimento também requer a parte corporal, emocional e perceptual de experiências vividas ou imaginadas ou introjetadas, 
conforme o caso, bem como o contexto sócio-cultural-espaço-temporal. Ambos, emoções e sentimentos associados "desempenham um papel essencial no comportamento social e, por extensão, no comportamento ético" No entanto, a dominação não aparece no corpo em todo o espaço do tempo da mesma maneira; as marcas corpóreas são inscrições socialmente estabelecidas pelo processo de dominação em que uma determinada sociedade está afundada. Desta forma, as marcas de sensibilidade nos discursos históricos fundamentais nos mostram uma época constitutiva, porém não determinista, do modo de apreciar-no-mundo (SCRIBANO, 2012) Nessa estrutura, identificamos que a história não é contada por nenhum assunto. A legitimidade da palavra é dada aos que colaboram na reprodução da "ordem dada" (KEMPER, 1990 apud COLLINS, 1981). Ou seja, os historiadores ocupam um lugar (entendido como dimensões de poder, status e distância) favorecido na reprodução do status quo e na definição pela disponibilidade de corpos. A idéia de lugar de Clark (KEMPER, 1990) nos permite pensar e investigar os discursos dos historiadores de Villa María e Villa Nueva, onde essas microhistórias apresentam um fardo e uma impressão pessoal, de modo que não reproduzem as emoções de assuntos coletivos, mas Temas individualizados com o primeiro e último nome que escreveu essa primeira historiografia local.

Nesse sentido, os historiadores são geradores recorrentes de mecanismos de apoio social que evitam sistematicamente conflitos sociais, por exemplo, através do que é concebido como "história oficial". Estes são constituídos como narrações e visões do corpo mundial, como uma interpretação de processos sociais construídos como uma sucessão de eventos e com o status de "verdade objetiva". Desta forma, como diz Scribano (2012), os mecanismos de viabilidade social operam nos quadros do senso comum, nas construções de sensações que parecem mais "íntimas" e "únicas" que cada indivíduo possui como agente social. Assim, os historiadores reproduzem uma história que se transforma, através de um processo, num discurso que cria emoções ligadas às posições expressas pelos escritores locais.

Além disso, os escritores constroem sensibilidades em torno de fantasmas e fantasias, por isso reescrevem uma particular historicidade de corpos e emoções, neste caso concreto, no relacionamento tensional Villa María-Villa Nueva cheio de esquecimento, ameaças, situações desejadas, isto é, como argumenta Scribano (2008), fantasias e fan- 
tasmas nunca fecham, são contingentes, mas sempre operam, tornam-se práticos.

Entre os historiadores que se posicionam como gurus da história oficial das origens de cada cidade, é necessário pensar toda a história, não apenas o contexto fundacional. Esses discursos históricos têm se preocupado em mostrar as características antagônicas que, desde suas origens, constituíam ambas as cidades com o objetivo de diferenciá-las, destacando a divisão proposta pelo rio e configurando o (s) território (s) -Villa Nueva e Villa María- com diferentes características. Costa e Mozejko (2001) argumentam que o que está em jogo não é tanto a verdade dos fatos do passado, mas sim controlar a definição de verdade em estratégias de história e discursivas utilizadas relacionam com as características que definem a competência dos atores sociais envolvidos na disputa desse poder. Assim, a tensão implícita na sensibilidade marcas impressas em vários discursos históricos existir e servir cada reutilização cidade na constituição de sua identidade coletiva configurado em torno de um olhar totalizante da história local. E a divisão das duas cidades é uma construção social que artificialmente dividido, assim são as histórias que não são experientes como processo, mas compartimentos como fragmentados que antagonicamente são como se o rio era mais do que um acidente natural "o, Natural naturalizada". Desde este ponto de vista que você colocar em xeque a naturalização dos discursos históricos hegemonicamente contados, mas especialmente a forma como os seus "porta-vozes" construiu e sensibilidades que fazem parte dos corpos e emoções dos agentes.

\section{Referências}

BACZKO, Bronislaw (1999). Los imaginarios sociales. Memorias y esperanzas colectivas. Paris: Nueva Visión.

BENJAMIN, W. \& ECHEVARRÍA, B. (2008). Tesis sobre la historia y otros fragmentos (No. 901 B4Y.). Universidad Autónoma de la Ciudad de México.

COSTA, Ricardo y MOZEJKO, Teresa (2001) El discurso como práctica. Lugares desde donde se escribe la historia. Rosario: Homo Sapiens.

CALVO, Bernardino (1989). Orígenes y desarrollo de la Ciudad de Villa María entre 1867 y 1967 y su relación con el surgimiento de los primeros barrios.

FISCHER e VERÓN, 1986__ Fischer, S., y Veron, E. (1986): "Théorie de l'énontiation et discours sociaux", Études de Lettres, 71.

FONSECA, Armando (2004). Historia de Villa Nueva... la del Rosario. Villa Nueva: Olivo 
Offset.

GIORDANO, Mariana, et. al. (editores) (2013), Memoria e imaginario en el Nordeste Argentino. Escritura, oralidad e imagen. Rosario: Prohistoria ediciones.

GRAMSCI, Antonio (2015). Antologías, Buenos Aires: Siglo XXI.

GRANADO, Pablo (2011). Villa Nueva "un pueblo con historia". $1^{\mathrm{a}}$ ed. Villa Nueva: Biblioteca Popular "Luis Roberto Altamira".

JELIN, Elizabeth (2002), El trabajo de la memoria. Buenos Aires: Siglo XXI.

KEMPER T. ed. (1990): Researh Agendas in the sociology of emotions. State University of New York.

LUNA ZAMORA, R. (2010) "La sociología de las emociones como campo disciplinario. Interacciones y estructuras sociales", en A. Scribano y P. Lisdero Sensibilidades en Juego: miradas múltiples desde los estudios sociales de los cuerpos y las emociones. Córdoba: CEA-CONICET.

MAGALLANES, G; GANDÍA, C; VERGARA, G (2014). Expresividad, creatividad y disfrute. Madrid: ESE-Editora y Universitas.

MELUCCI, Alberto (2001). Vivencia y convivencia. Teoría social para una era de la información. Madrid: Trotta.

PEDERNERA, José (1970). Historia de la ciudad de Villa María. Centro de Investigaciones Históricas Ramón J. Cárcano de la Escuela Normal Víctor Mercante.

PEREYRA, Luciano (2012).Villa Nueva y la provincia en la época rosista. Villa María: Ediciones del Crecimiento Cristiano.

RÜEDI, Rubén (2016). Historia de Villa María. $1^{a}$ edición. Villa María: El Narval Ediciones.

SCRIBANO, Adrían (2008). Fantasmas y Fantasías Sociales: notas para un homenaje a T.W. Adorno desde Argentina. Revista Intersticios, vol. 2.

Adrían. (2009)A modo de epílogo ¿Por qué una mirada sociológica de los cuerpos y las emociones? SCRIBANO, A; FÍGARI, C. (comps.). Cuerpo (s), Subjetividad (es) y Conflicto (s): Hacia una sociología de los cuerpos y las emociones desde Latinoamérica. Buenos Aires: CLACSO/Ciccus. p. 141-151.

Adrían. (2012). Sociología de los cuerpos/emociones. Revista Latinoamericana de Estudios sobre Cuerpos, Emociones y Sociedad, vol. 4, no 10. 